\title{
Experimental logging alters the abundance and community composition of ovipositing mosquitoes in the southern Appalachians
}

\author{
M. C A M I L E H O P I N S, ${ }^{1,2}$ C O U R T N Y A. TH O M A S O N, ${ }^{1}$ \\ B R Y A N L B R O W N, ${ }^{1}$ L A I L A T. K I R K P A T R I C K, ${ }^{1}$ \\ S A L LY L. PA U L S N ${ }^{3}$ and D A N M . H A W L E Y ${ }^{1}{ }^{1}{ }^{1}$ Department of Biological \\ Sciences, Virginia Tech, Blacksburg, Virginia, ${ }^{2}$ U.S. Geological Survey, Office of Ecosystems, Reston, Virginia, and ${ }^{3}$ Department of \\ Entomology, Virginia Tech, Blacksburg, Virginia,
}

\begin{abstract}
The loss of intact forest via logging can influence vector-borne disease dynamics in part by altering the abundance or diversity of mosquito species. Using an experimental field approach, we characterised how two types of logging (clearcut and repeat-entry shelterwood) affected temperate forest mosquito abundance and diversity in southwestern Virginia.

2.From May to September in 2008-2010, infusion-baited gravid traps were used to collect ovipositing female mosquitoes across experimental forest plots that varied in logging treatment. Of the 29680 collected adult female mosquitoes, the three dominant taxa captured were Aedes triseriatus (55\%), Aedes japonicus (21\%), and Culex pipiens/restuans (20\%).

3. Logging treatment had a significant effect on the overall number of female mosquitoes caught per trap night, with lower average abundance of females on both logged treatments relative to two types of unlogged, control plots. When the three most abundant mosquito species were examined separately, logging treatment significantly influenced the abundance of both Aedes species, but did not significantly affect $C$. pipiens/restuans abundance.

4. Logging treatment did not influence the richness or diversity of mosquito species captured in gravid traps. However, logging treatment significantly altered the multivariate community composition of captured mosquitoes, an effect probably mediated by differential species-specific impacts of logging on abundance.

5. Overall, the results of the present study suggest that the risk of arboviruses transmitted by container-breeding Aedes species may be lower following a logging event in Appalachian forests because of reduced A. japonicus and A. triseriatus abundance with logging.
\end{abstract}

Key words. Abundance, community composition, logging, mosquito, richness, vector.

\section{Introduction}

As human populations increase, the associated demand on natural resources has resulted in a global loss of intact forests (Tilman et al., 2011; Hansen et al., 2013). Forest disturbance and loss have been shown to reduce biodiversity for a suite

Correspondence: M. Camille Hopkins, U.S. Geological Survey, Office of Ecosystems, 12201 Sunrise Valley Drive, MS 300, Reston, VA 20192.

E-mail: mchopkins@usgs.gov of taxa (e.g. Belote et al., 2008; Duraes et al., 2013; Burivalova et al., 2014), and these changes in biodiversity can have critical downstream consequences for disease risk (Keesing et al., 2006, 2010; Pongsiri et al., 2009). Past work on biodiversity and disease has largely focused on how anthropogenic disturbance to forests alters the diversity and abundance of vertebrate reservoirs of zoonotic diseases (e.g. Nupp \& Swihart, 1998), and, in turn, how these changes in reservoir abundance and diversity influence zoonotic disease risk (e.g. Allan et al., 
2009). Although the impacts of deforestation on vector ecology and resulting disease risk have been of long-standing interest (reviewed in Walsh et al., 1993), only recently have studies explicitly considered how anthropogenic changes to intact forests alter the diversity and abundance of the invertebrate taxa that commonly serve as disease vectors (e.g. Thongsripong et al., 2013; Meyer Steiger et al., 2016; Zhody et al., 2016).

While the influence of logging on invertebrate vectors has not been fully examined, there have been several studies on the responses of non-vector invertebrate populations and communities to logging. Lepidoptera abundance and diversity (Ghazoul, 2002; Savilaakso et al., 2009), and the abundance or diversity of tropical beetles, termites, and ants (Ewers et al., 2015) have all been shown to decline with logging, and a meta-analysis of responses to logging for several animal taxa found a general decline in invertebrate richness with logging intensity (Burivalova et al., 2014). However, responses to logging were shown to be highly taxon-specific within invertebrate communities in southwestern Australia (Strehlow et al., 2002).

Few studies to date have examined responses of mosquito vectors to deforestation and both focused on larval abundance. Batzer et al. (2005) found a higher abundance of Culicine mosquito larvae on logged bottomland sites in South Carolina, U.S.A. In contrast, Barros and Honório (2015) found very low abundance of Anopheles darlingi larvae in deforested ponds on agricultural settlements of the Brazilian Amazon. Instead, A. darlingi larvae were at their highest abundance in 'transitional ponds' at the fringes of forest patches, which the authors hypothesise may have been created by nearby logging events that obstructed water flow (Barros \& Honório, 2015). The influence of logging per se on adult mosquito communities has not yet been directly examined, but several prior studies have examined how urbanisation or land-use gradients, which integrate a suite of landscape changes including loss of intact forest, influence adult mosquito communities. Studies of land-use gradients in the Peruvian Amazon (Johnson et al., 2008), Thailand (Thongsripong et al., 2013), Spain (Ferraguti et al., 2016), Madagascar (Zhody et al., 2016), and remote Australian islands (Meyer Steiger et al., 2016) generally find the highest mosquito abundance and diversity in rural, forested sites with high vegetative cover relative to more urban habitats. However, in Anopheles species, the combined effects of deforestation and conversion to agriculture are highly species-specific, with some taxa increasing in abundance with land-use change, and others decreasing (Yasuoka \& Levins, 2007). Overall, because all of these prior studies were correlational, it remains unknown whether logging per se or some other correlate of land use altered the abundance and diversity of mosquito communities. Experimental logging studies are needed to determine how logging influences the abundance and diversity of the adult female mosquitoes that commonly serve as disease vectors.

Using a silvicultural experimental approach that applied two types of logging treatment (single-entry clearcut, and repeated-entry shelterwood harvesting) to otherwise similar forest plots, here we sought to understand how logging influences the abundance, diversity, and community composition of mosquitoes in southwest Virginia. As this assemblage includes the vectors of avian malaria (Kimura et al., 2010; Farajollahi et al., 2011), reptile haemogregarines (Smith et al., 1996; Harkness et al., 2010), filarial worms (Ledesma \& Harrington, 2011; Mehus \& Vaughan, 2013), and arboviruses (West Nile virus, La Crosse encephalitis virus; McJunkin et al., 1998; Turell et al., 2001; Haddow et al., 2011), any detected responses to logging in this area may influence the spatial distribution of mosquito-borne pathogens. We hypothesised that logging of intact temperate forests would alter the abundance and community composition of mosquitoes. Based on the results of mosquito urban gradient studies (e.g. Johnson et al., 2008; Thongsripong et al., 2013), we predicted that intact undisturbed forest would have greater mosquito diversity and species richness, with a lower abundance of disease vectors than logged sites.

\section{Materials and methods}

\section{Study site}

Our primary study sites in Jefferson National Forest in southwestern Virginia were part of a long-term investigation of silvicultural oak regeneration methods on biodiversity (e.g. Belote et al., 2008; Atwood et al., 2009), termed the Southern Appalachian Silviculture and Biodiversity Project (SASAB; Fig. 1). These oak-dominant (Quercus spp.) sites had similar overstorey composition, age and topographic position on moderate (10-40\%), south-facing slopes (Belote et al., 2008). Two SASAB sites used for this study (Blacksburg 1 and 2; BB1 and $\mathrm{BB} 2$, respectively) were located in Montgomery County, VA $\left[37^{\circ} 17^{\prime} 35.73^{\prime \prime} \mathrm{N}, 80^{\circ} 27^{\prime} 24.63^{\prime \prime} \mathrm{W}\right.$ (BB1); $37^{\circ} 18^{\prime} 20.35^{\prime \prime} \mathrm{N}$, $80^{\circ} 26^{\prime} 24.95^{\prime \prime} \mathrm{W}$ (BB2)] while a third site [Newcastle (NC)] was located in Craig County, VA $\left(37^{\circ} 27^{\prime} 20.78^{\prime \prime} \mathrm{N}, 80^{\circ} 23^{\prime} 0.37^{\prime \prime} \mathrm{W}\right)$. A single non-SASAB site (BB3) located near BB1 and BB2 in Montgomery County, VA (Fig. 1), was established as a fourth site for the purposes of this study (see the section on 'Contiguous control site' for further details).

\section{Silvicultural logging treatments}

At each of the three SASAB study sites (BB1, BB2, and $\mathrm{NC}$ ), seven 2-ha experimental units (EUs) were established with no buffer between the units. As part of the broader SASAB project, silvicultural treatments were randomly assigned to EUs within sites using a fully randomised complete block design (Belote et al., 2008; Homyack \& Haas, 2013). For this study, three of the SASAB silvicultural treatments were the focus of mosquito surveillance: repeated-entry shelterwood plots (SW) at $0-2$ years post-logging; single-entry clearcut (CCUT) plots at 12-14 years post-logging; and unlogged control plots embedded in a matrix of surrounding fragmentation created by silviculture treatments, thus termed 'embedded controls' (ECON) at $80-100$ years old. These three silvicultural treatments were replicated across three SASAB study sites - BB1, BB2, and NC (Table 1; Fig. 1) - for the purposes of this study.

The three SASAB treatments (ECON, CCUT, and SW) differed in the extent and frequency of harvesting, as well as the time elapsed since the last logging event. Embedded control 


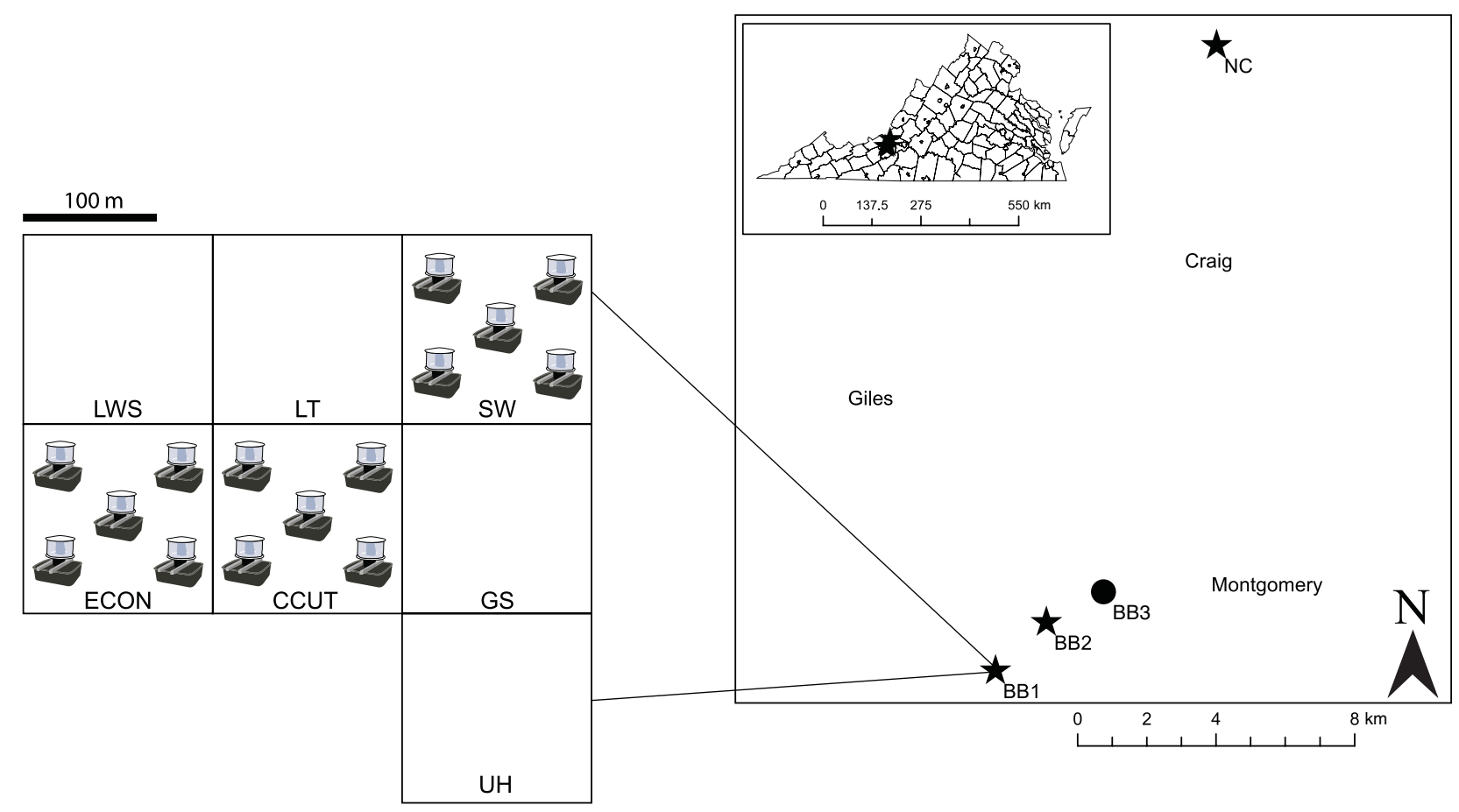

Fig. 1. The spatial arrangement of study sites where mosquito abundance and community composition were characterised using gravid traps. The right-hand map shows the distribution of the four study sites (BB1, Blacksburg 1; BB2, Blacksburg 2; BB3, Blacksburg 3; NC, Newcastle) across two counties (Montgomery and Craig), and the inset shows the location of study sites within southwest Virginia. The left-hand figure shows an example layout of the three experimental units sampled at the BB1 study site. Due to experimental randomisation, the spatial arrangement of silviculture treatment assignments differed across the three Southern Appalachian Biodiversity Silviculture and Biodiversity (SASAB) study sites (BB1, BB2, and NC; stars). At each SASAB site, three of the seven 2-ha silvicultural treatments (SW, repeat-entry shelterwood; CCUT, clearcut; ECON, embedded control) were used for this study, but other treatments (LWS, low-leave shelterwood; LT, leave tree cut; GS, group selection; UH, understorey herbicide) are shown to illustrate the matrix of habitat within which each experimental unit was embedded. After a minimum 30-m buffer zone was established on each treatment, five infusion-baited gravid traps were placed on each experimental unit as shown. Gravid traps are not shown to size. [Colour figure can be viewed at wileyonlinelibrary.com].

Table 1. Experimental design of silvicultural disturbance treatments. We had 11 total experimental units made up of four treatments replicated across four study sites (BB1, Blacksburg 1; BB2, Blacksburg 2; BB3, Blacksburg 3; NC, Newcastle). Although three treatments [embedded control (ECON), clearcut (CCUT), and repeat-entry shelterwood (SW)] were balanced across the Southern Appalachian Silviculture and Biodiversity Project (SASAB) sites, the overall study design was unbalanced, with contiguous control (CCON) experimental units only present at the BB3 site.

\begin{tabular}{|c|c|c|c|c|c|}
\hline \multirow{4}{*}{$\begin{array}{l}\text { Stand age } \\
\text { Study sites }\end{array}$} & \multirow[b]{4}{*}{ County } & \multicolumn{4}{|c|}{ Logging treatments } \\
\hline & & CCON & ECON & CCUT & SW \\
\hline & & $100-130$ years & $80-100$ years & $12-14$ years & $0-2$ years \\
\hline & & & SASAB sites & & \\
\hline BB1 & Montgomery & 0 & 1 & 1 & 1 \\
\hline BB2 & Montgomery & 0 & 1 & 1 & 1 \\
\hline $\mathrm{NC}$ & Craig & 0 & 1 & 1 & 1 \\
\hline BB3 & Montgomery & 2 & 0 & 0 & 0 \\
\hline TOTAL & & 2 & 3 & 3 & 3 \\
\hline
\end{tabular}

(ECON) plots never experienced any direct logging, but these experimental units were directly adjacent to disturbed units with no buffer zone (Fig. 1). Clearcut (CCUT) plots were logged once between 1995 and 1996 (Atwood, 2008), 12-14 years before study initiation, and this harvest removed $95 \%$ of the basal overstorey area. At this initial harvest in 1995-1996, SW sites underwent stand thinning with $56 \%$ of the basal area removed.
Approximately 12 years after initial stand thinning, all residual overstorey stems on the SW were logged between 2007 and 2008 (Homyack \& Haas, 2013), just prior to the initiation of this study. Thus, at the time of this study, the SW plots had the youngest stand age ( $0-2$ years) and the most recent logging event, followed by the CCUT plots which had not experienced any direct harvesting for 12-14 years, and the ECON plots which were not 


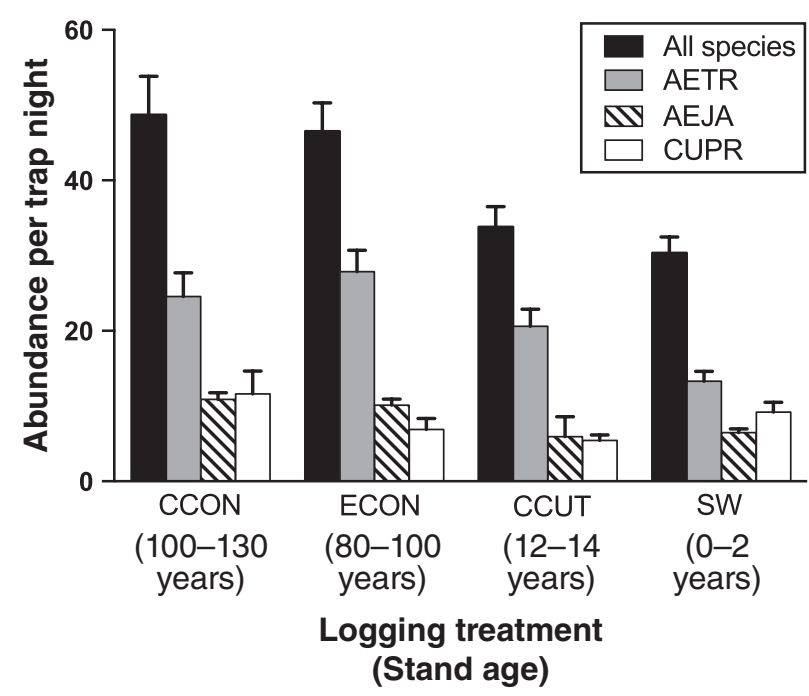

Fig. 2. Mean number $( \pm$ SE) of female mosquitoes caught per night in gravid traps across four experimental logging treatments $(\mathrm{CCON}$, contiguous control; ECON, embedded control; CCUT, clearcut; $\mathrm{SW}$, repeat-entry shelterwood). Results are presented for all mosquitoes combined (black bars) as well as for the three most commonly collected mosquito species or species groups: Aedes triseriatus (AETR; grey), Aedes japonicus (AEJA; hatched), and Culex pipiens/restuans (CUPR; white). Although treatments are ordered by stand age for visual clarity, treatments were considered as categorical factors for analysis.

directly logged in the last $80-100$ years. Accordingly, the density of overstorey trees at the time of the study (measured in 2009) was highest on ECON sites, intermediate on CCUT sites, and lowest on SW sites (Fig. 2D in Homyack \& Haas, 2013). As time since disturbance and the type of silvicultural disturbance applied were confounded in our study design (i.e. the SW and CCUT treatments differed in both variables), we conservatively considered logging treatment as a categorical variable for statistical analysis. However, because logging was most recent on the SW treatments and these plots had the lowest diameter at breast height value at the time of vector sampling, we expected that the effects of logging on mosquito abundance and community composition would be strongest for the SW treatments.

\section{Contiguous control site}

Due to the matrix of forest fragmentation created by the SASAB experimental design (Fig. 1) and associated disturbance to ECON experimental units (e.g. skid trails, diffuse light from adjacent treatments), we established an additional non-SASAB study site (BB3) containing two contiguous control (CCON) experimental units equivalent in size to the SASAB EUs. The BB3 site $\left(37^{\circ} 18^{\prime} 48.59^{\prime \prime} \mathrm{N}, 80^{\circ} 25^{\prime} 15.82^{\prime \prime} \mathrm{W}\right)$ was also located in Jefferson National Forest (Montgomery County), just adjacent to BB1 and BB2 (Fig. 1). These undisturbed experimental units were embedded within large areas of contiguous forest that had not been recently disturbed by harvesting. Similar to the nearby SASAB sites, these stands were dominated by oak (Quercus spp.) along with yellow poplar (Liriodendron tulipifera). The ages of the dominant and co-dominant trees in these stands were 100-130 years. Similar to the SASAB sites, the stands are on a south aspect with a moderate slope (J. Overcash, US Forest Service, pers. comm.).

\section{Mosquito sampling}

From late May to September 2008-2010, adult mosquitoes were collected twice a week from hay infusion-baited gravid traps (Scott et al., 2001; Jackson et al., 2005). Although gravid traps generally capture lower species diversity than light traps (e.g. Chen et al., 2011), we were most interested in the arboviral vectors present in our study area, which include Aedes japonicus and Aedes albopictus (vectors of La Crosse virus), and Culex pipiens/restuans (vectors of West Nile virus). All three species will readily use gravid traps (Reiter et al., 1986; Scott et al., 2001; Jackson et al., 2005). Gravid traps select for ovipositing or blood-fed female mosquitoes that are more likely to be infected with arboviruses compared with non-gravid females (Williams $\&$ Gingrich, 2007). We baited our gravid traps with a hay infusion comprising $114 \mathrm{~g}$ of straw, $1 \mathrm{~g}$ of lactalbumen, $1.32 \mathrm{~g}$ of brewer's yeast, and 26.5 litres of warm tap water (Reiter, 1986). Five infusion-baited gravid traps were placed on each EU ( $n=11$ total; Table 1$)$ in a standardised arrangement on each plot (Fig. 1). A minimum 30-m buffer zone was applied to each EU to minimise edge effects. After a minimum of 24-h storage in a freezer at $-80{ }^{\circ} \mathrm{C}$, all captured female mosquitoes were identified using morphological keys (Slaff \& Apperson, 1989; Darsie, 2002). As important adult taxonomic characters may be damaged or missing after field collection (Saul et al., 1977, Harrington \& Poulson, 2008), which makes identification difficult, $C$. restuans and $C$. pipiens mosquitoes were pooled. Such pools will hereafter be referred to as $C$. pipiens/restuans.

\section{Statistical analysis}

We used the statistical package $\mathrm{R}$ version 3.3.2 ( $\mathrm{R}$ Development Core Team, 2016) for all analyses. We examined the effect of logging treatment on the total abundance of female mosquitoes (the number of mosquitoes captured per trap night) and the separate abundance of each of the three most commonly detected mosquito taxa on our sites (A. japonicus, Aedes triseriatus, and $C$. pipiens/restuans) using generalised linear mixed models (GLMMs) with the glmmPQL function in the MAss package (Venables \& Ripley, 2002). This package fits GLMMs with a penalised quasi-likelihood function using a Laplace approximation. We specified a Poisson distribution for all abundance models to account for non-normally distributed count data. Each model included treatment (categorical factor: CCON, ECON, CCUT, or SW), county (categorical factor: Montgomery or Craig), and temporal variables (month and year, as categorical factors) as fixed effects. We include county in all models because the NC site, located in a separate county, was spatially isolated from the other three study sites (Fig. 1). To account for the non-independence of repeated measures from each EU, we included Julian date nested within the ID of each EU ( $n=11$ total; Table 1$)$ as a random effect; and we 
used a first-order autocorrelation structure (ar1) to account for longitudinal repeated measures. For each model, parameter significance was determined using type III Wald $\chi^{2}$ tests with significance at $P<0.05$. In cases where the overall effect of logging treatment was significant, we used parameter effect tests to examine how each logging treatment differed from the reference treatment, set as the CCON treatment.

We compared the community composition of mosquitoes detected in our gravid traps across logging treatments using univariate and multivariate metrics in the vegan package of $\mathrm{R}$. For our univariate metrics, we evaluated two diversity indices that span values of the $q$ order: species richness (the total number of species detected) and Simpson's diversity index (Keylock, 2005; Jost, 2009). We analysed the univariate metrics using GLMMs, again with the glmmPQL function in the MAss package. We specified a Poisson distribution for the species richness model (because richness data are positive integers) and negative binomial distributions for Simpson's index, which is bounded to fall between 0 and 1. Again, each model included treatment (categorical factor: CCON, ECON, CCUT, or SW), county (categorical factor: Montgomery or Craig), and temporal variables (month and year, as categorical factors) as fixed effects. As with the abundance models, to account for the non-independence of repeated measures from each EU, we included Julian date nested within the ID of the EU as a random effect; and we used a first-order autocorrelation structure ( $\operatorname{ar} 1)$ to account for longitudinal repeated measures.

The multivariate community composition of mosquitoes detected by our gravid traps was examined with nonmetric multidimensional scaling (NMDS) (Kruskal, 1964) and permutational multivariate analysis of variance (PERMANOVA) (Anderson, 2001), both using Bray-Curtis dissimilarities. Our PERMANOVA included effects of treatment (CCON, ECON, CCUT, or SW), county (Montgomery or Craig), site (BB1, $\mathrm{BB} 2, \mathrm{BB} 3$, and NC), month, and year. In order to account for the non-independence of our longitudinal sampling data, the community composition of trapped mosquitoes was averaged for each month within experimental unit, producing up to five values for community composition for each EU per year. We used a Scree plot of stress versus number of solution dimensions to choose the number of axes for our NMDS solution. The decision was based on finding the most parsimonious solution, i.e. the smallest number of axes, while still obtaining a good fit for the solution based on stress (McCune \& Grace, 2002). Results of the NMDS are presented as a plot of the bivariate means of the monthly mosquito communities for each experimental unit.

\section{Results}

We collected 29680 female mosquitoes representing 15 species over three field seasons (2008-2010). The three most commonly collected species were A. triseriatus (55\%), A. japonicus (21\%), and C. pipiens/restuans (20\%) (Table 1), all of which are in the subfamily Culicinae. Aedes triseriatus was the most commonly collected species, and the most common genera encountered from highest to lowest abundance were Aedes (six species), Culex (three species), and Anopheles (two species).
Logging treatment had a significant effect on the overall abundance of females collected per night by our gravid traps (Fig. $2 ; \chi^{2}=10.1$, d.f. $=3, P=0.018$ ). On average, the number of female mosquitoes collected per trap night declined with stand age (Fig. 2), but parameter effect tests showed that none of the treatments differed significantly from the reference CCON treatment (Table S2). Sampling month $\left(\chi^{2}=115.0\right.$, d.f. $=5$, $P<0.0001)$ and year $\left(\chi^{2}=69.6\right.$, d.f. $\left.=2, P<0.0001\right)$ also significantly predicted total female mosquito abundance per trap night (see Table S2 for directionality of month and year effects). The county in which the sampling site was located (Montgomery or Craig) did not predict the overall abundance of female mosquitoes per trap night $\left(\chi^{2}=0.02\right.$, d.f. $\left.=1, P=0.88\right)$.

When we examined the three most commonly collected mosquito species separately, logging treatment had significant effects on the abundance of $A$. japonicus $\left(\chi^{2}=21.9\right.$, d.f. $=3$, $P<0.0001)$ and $A$. triseriatus $\left(\chi^{2}=8.17\right.$, d.f. $=3, P=0.043$; Fig. 2). For A. japonicus, abundances of females in the CCUT and SW treatments were significantly lower than in the CCON reference treatment (Table S3). For A. triseriatus, parameter estimates were negative for both the CCUT and SW treatments but not statistically significant (Table S4). Similar to results for overall abundance, sampling month and year were both strong predictors of the abundance of female A. japonicus and A. triseriatus (month, $\chi^{2} \geq 59.4$, d.f. $=5, P<0.0001$ for both species; year, $\chi^{2} \geq 85.3$, d.f. $=2, P<0.0001$; Tables S3 and S4), whereas county was not a significant predictor for either species $\left(\chi^{2} \leq 3.01\right.$, d.f. $\left.=1, P>0.078\right)$. For $C$. pipiens/restuans, logging treatment did not significantly affect the abundance of females collected per trap night $\left(\chi^{2}=7.14\right.$, d.f. $\left.=3, P=0.067\right)$, although sampling month $\left(\chi^{2}=65.2\right.$, d.f. $\left.=5, P \ll 0.0001\right)$, year $\left(\chi^{2}=229.6\right.$, d.f. $\left.=2, P \ll 0.0001\right)$, and county $\left(\chi^{2}=5.48\right.$, d.f. $=1, P=0.019)$ were all significant predictors of $C$. pipiens/restuans abundance (Table S5).

Logging treatment was not a significant predictor of either univariate diversity metric for the females collected in our gravid traps (Fig. 3): species richness $\left(\chi^{2}=3.32\right.$, d.f. $\left.=3, P=0.33\right)$ or Simpson's index $\left(\chi^{2}=1.79\right.$, d.f. $\left.=3, P=0.69\right)$. Sampling month significantly predicted both indices (both $\chi^{2} \geq 100.9$, d.f. $=5, P \ll 0.0001)$ while sampling year predicted Simpson's index $\left(\chi^{2}=9.11\right.$, d.f. $\left.=2, P=0.010\right)$ but not species richness $\left(\chi^{2}=0.88\right.$, d.f. $\left.=2, P=0.64\right)$. In contrast, the county in which the study site was located (Montgomery or Craig) significantly predicted species richness $\left(\chi^{2}=9.83\right.$, d.f. $\left.=1, P=0.0017\right)$ but not Simpson's diversity index $\left(\chi^{2}=0.97\right.$, d.f. $=1$, $P=0.32)$.

Two dimensions were chosen for NMDS based on a Scree plot and associated stress values (0.07). Logging treatment significantly influenced the multivariate composition of the mosquito community detected by gravid traps $\left(F_{3,143}=2.98, P=0.001\right.$, $R^{2}=0.04 ; \quad$ Fig. 4). Study site $\left(F_{2,143}=0.64, \quad P=0.017\right.$, $\left.R^{2}=0.02\right)$, year $\left(F_{1,143}=1.38, P<0.001, R^{2}=0.05\right)$, and month $\left(F_{5,143}=7.33, P<0.001, R^{2}=0.25\right)$ were also significant predictors of multivariate composition, with month having the highest predictive power. The county in which the study site was located $\left(F_{1,143}=1.46, P=0.18, R^{2}=0.01\right)$ did not predict the composition of the mosquito community detected by gravid traps. 


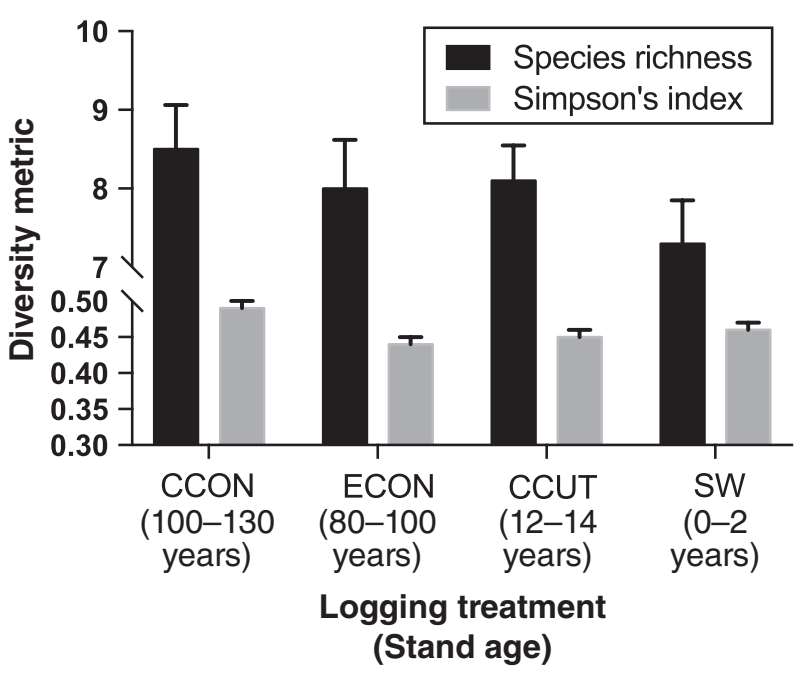

Fig. 3. Mean ( \pm SE) species richness (black) and Simpson's diversity index (grey) for mosquito communities detected by gravid traps across four experimental logging treatments (CCON, contiguous control; ECON, embedded control; CCUT, clearcut; SW, repeat-entry shelterwood). Although treatments are ordered by stand age for visual clarity, treatments were considered as categorical factors for analysis.

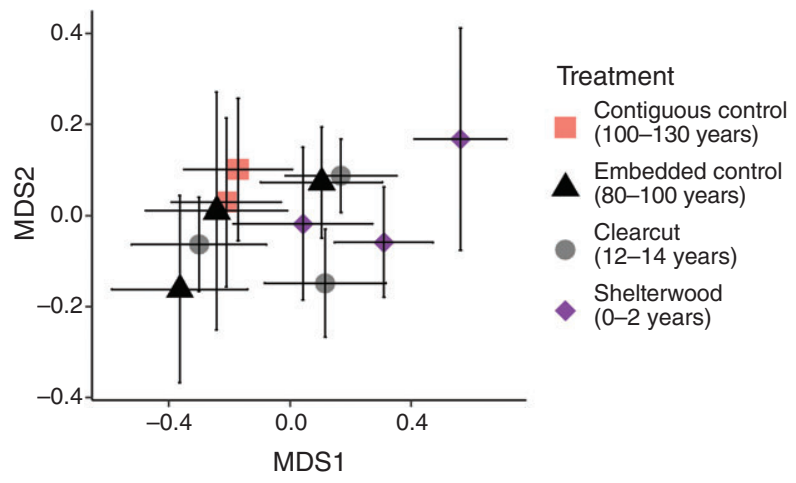

Fig. 4. Multivariate ordination of mosquito communities detected by gravid traps from the four logging treatments. Data were averaged for a given month within experimental units $(n=11)$ to account for temporal and spatial non-independence. Bivariate means of the monthly values are presented for each experimental unit $(n=11$; Table 1). [Colour figure can be viewed at wileyonlinelibrary.com].

\section{Discussion}

We found that the abundance and community composition of oviposition site-seeking mosquitoes in temperate Appalachian forests were significantly affected by experimental timber harvesting. Both types of logging resulted in lower abundances of all collected mosquitoes, and in particular, lower abundances of A. japonicus and A. triseriatus relative to undisturbed contiguous forest. Furthermore, logging significantly shifted the multivariate composition of the mosquito assemblage detected by gravid traps. However, the richness and diversity of the detected mosquito community was unaffected by logging, perhaps due to the sampling technique (gravid traps) used in our study. Overall, because vector abundance is a key predictor of vector-borne disease risk (Antonovics et al., 1995; Mather et al., 1996), our results suggest that the risk of pathogens transmitted by A. japonicus and A. triseriatus may be lower following a logging event in Appalachian forests.

The detected mosquito assemblage at our sites was dominated by the tree-hole mosquito (A. triseriatus), the primary vector of La Crosse virus (Watts et al., 1972). Although our use of gravid traps probably influenced the dominant species collected, a study in the Appalachian mountains of western North Carolina also found strong dominance of A. triseriatus using a suite of collection techniques (Szumlas et al., 1996). A recently established invasive species, the Asian bush mosquito (A. japonicus; Kaufman \& Fonseca, 2014), was the second most abundant species collected. Aedes japonicus is a vector of La Crosse virus (Sardelis et al., 2002; Harris et al., 2015), West Nile virus (Sardelis \& Turell, 2001; Turell et al., 2005), and Cache Valley virus (Yang et al., 2018). Logging treatment significantly affected the abundance of both of these Aedes species, with the average abundance of female $A$. triseriatus and japonicus declining with stand age (Fig. 2). Consistent with these results, Bova (2014) found lower egg and adult abundance of A. triseriatus, $A$. japonicus, and A. albopictus on logged treatments at a subset of the SASAB sites in 2011. Thus, the detected declines in overall mosquito abundance with logging are probably driven largely by responses of the container-breeding Aedes species common to our Appalachian study sites. Interestingly, previous work by Batzer et al. (2005) found the highest abundance of immature marsh and open-water Aedes on logged bottomland sites in South Carolina, demonstrating that some Aedes species increase in abundance with logging. Together with our results, this suggests that responses of Aedes species to logging may be either positive or negative depending on oviposition-site preference.

Culex pipiens/restuans were the third most abundant community members detected in our study and are known vectors of West Nile virus (Turell et al., 2005). In contrast to the two Aedes species that we detected most commonly on our sites, the pooled abundance of female $C$. pipiens/restuans was not significantly affected by logging treatment in our study, and there was no apparent directional shift in abundance with logging for this group (Fig. 2). As C. pipiens and C. restuans are generalists that readily breed in both natural and disturbed habitats (e.g. Johnson et al., 2015), it is perhaps not surprising that these species were largely unaffected by logging. Furthermore, our results are in accordance with other Culex gravid trap studies that found no difference in Culex abundance across land-use type, including fragmented forest (Gardner et al., 2014; Karki et al., 2016). Although our inability to morphologically discriminate between $C$. pipiens and $C$. restuans limits our inference for the Culex species, the zoonotic disease vectors most abundant at our site appear to have been differentially affected by logging, with the two most abundant Aedes species significantly impacted by logging and the two pooled Culex species largely unaffected. However, because the two pooled Culex species can differ in their temporal dynamics (Jackson \& Paulson, 2006) and contributions to disease transmission (e.g. Kilpatrick et al., 2010), species-specific identification is a critical next step for understanding how logging may impact Culex populations. 
Our abundance results suggest that closed-canopied forests (i.e. our two control treatments) are more favourable than recently logged habitat for the two container-breeding Aedes species detected in large numbers on our study sites. Nonetheless, because we did not measure specific environmental variables or habitat characteristics, our study was not able to identify the specific mechanisms that underlie the detected changes in the abundance of female A. japonicus and A. triseriatus with logging. Silvicultural practices such as logging can influence mosquito abundance through multiple non-exclusive mechanisms, including changes in both microhabitat (e.g. sunlight levels, temperature, creation of temporary pools, and frequency of drying events) and macrohabitat (e.g. removal of overstorey canopy cover and trees with associated treeholes). These abiotic differences can have direct effects on mosquito survival (e.g. Zhong et al., 2016) and larval development rate (e.g. Couret et al., 2014). Furthermore, these abiotic differences can indirectly influence mosquito populations by altering biotic factors such as food availability (e.g. Yee et al., 2012) or the abundance of competitors or predators (e.g. Juliano, 2009). As the Aedes species detected most commonly at our sites both breed readily in tree holes (Kaufman \& Fonseca, 2014), effects of logging on the abundance of A. triseriatus and A. japonicus are most likely related to the reduced availability of oviposition sites following a logging event. Past research has shown that partial harvesting (SW) on the SASAB study sites decreases stump sprouting, which is important for tree regeneration (Atwood, 2008; Atwood et al., 2009), and thus creation of oviposition sites like rot holes and pans (Kitching, 1971). Studies of host-seeking mosquitoes have also shown that tree density is an important predictor of mosquito abundance, which the authors hypothesise is due to the limited movement of adult females away from the larval sites from which they emerged (O'Brien \& Reiskind, 2013). Thus, a decline in oviposition site availability is the most likely driver of the declines in the abundance of female A. japonicus and A. triseriatus with logging. However, other factors such as differences in shade and temperature, or context-dependent biotic interactions such as larval competition or predation (e.g. Juliano 2009), may also contribute to the declines in these two Aedes species with logging.

Logging treatment significantly shifted the multivariate community assemblage detected by our gravid traps. Because we used a Bray-Curtis metric that quantifies differences in the relative abundance rather than presence or absence of species (Legendre \& Legendre, 1998), the detected community-level shifts are probably a result of differential effects of logging on the abundance of the two most commonly detected Aedes species versus the $C$. pipiens/restuans complex (Fig. 2), which altered the relative abundance of the most common vectors on our study sites. Overall, our findings indicate that logging results in a significant shift in the multivariate composition of the female mosquito community detected by gravid traps. However, logging treatment explained a relatively small percentage of the multivariate distance (4\%), in contrast to month, which explained $25 \%$ of variation. Thus, while logging treatment did shift the relative abundance of the oviposition site-seeking mosquito community, these shifts were still minor relative to seasonal effects. Furthermore, because our two logged treatments (shelterwood and clearcut) differed both in the length of time since the last logging disturbance and in the type of silvicultural treatment applied, our study design is unable to definitively tease apart potential temporal effects of disturbance from effects of specific silvicultural practices on mosquito communities.

In contrast to the multivariate results, we did not detect any effects of logging on the diversity or richness of the mosquito community detected by gravid traps. Although species richness was generally higher on plots of older stage age (Fig. 3), there were no significant effects of logging treatment on either univariate diversity metric. These results differ from previous studies in Peru, Thailand, and Australia, which found strong declines in mosquito community diversity in more urbanised landscapes (Johnson et al., 2008; Thongsripong et al., 2013; Meyer Steiger et al., 2016). Because our study specifically isolated the effects of logging, it is possible that other characteristics of urbanisation explain the previously detected, much stronger, decreases in community diversity across a broad degradation or urbanisation gradient. On the other hand, lack of logging effects on mosquito diversity may be largely an artifact of the sampling methods we used. Previous studies that found effects of urbanisation on mosquito diversity (Johnson et al., 2008; Thongsripong et al., 2013; Meyer Steiger et al., 2016) used traps that were selective for host-seeking mosquitoes (e.g. light traps, BG sentinel), whereas this study used gravid traps, which were selective for ovipositing females. Our trap selection may have hindered the detection of rare species, and thus robust quantification of community diversity, because gravid traps are known to selectively attract Culex and container-breeding Aedes species (Scott et al., 2001; Jackson et al., 2005), but are not ideal for sampling other genera. In order to more robustly determine how logging influences diversity of the mosquito assemblage, a variety of trapping methods should be employed in future studies.

In summary, we found that experimental logging of temperate forests reduced the abundance of oviposition site-seeking mosquitoes detected by gravid traps, and this reduction was driven by the two common Aedes species on our study sites. In contrast, C. pipiens/restuans did not show a directional response to logging. These differential species-specific responses caused a significant shift in the overall assemblage of female mosquitoes detected by gravid traps on logged sites. Furthermore, in the case of the clearcut treatments, the detected effects of logging on female abundance persisted for up to at least 12 years post-logging, when our study began. The declines in abundance of A. japonicus and A. triseriatus females post-logging suggest that mosquito-borne disease risk for particular pathogens, such as La Crosse virus (Watts et al., 1972; Harris et al., 2015), may also be lower at this time. Nevertheless, because mosquito-borne disease risk is influenced by many factors that we did not measure, including human biting rate and parasite development in the vector, future studies should examine how logging influences a suite of traits relevant for predicting vector-borne disease dynamics. Overall, further research is needed to understand the impact of the projected accelerating rates of deforestation (Tilman et al., 2011) on mosquito populations and communities. 


\section{Acknowledgements}

We thank Nate Lambert, Allen Patton, R. J. Wilding, Jake Bova, Bonnie Fairbanks, Cari Lynn Squibb, Noah Thrope, Kylie Perkins, Lindsey McAlexander, Genevieve Dudzinsky, Jennifer Miller, and Laila Kirkpatrick for field and laboratory assistance. We thank James Adelman for statistical analysis assistance. We thank Jesse Overcash, Travis Belote, Bob Jones, and Carola Haas for assistance with SASAB logistics. Finally, we thank Tara Craig and Jennifer Smith for assistance with Figure 1 and multiple anonymous reviewers for helpful comments on the manuscript. Research funding was supported in part by Virginia Tech, Sigma Xi and an NIH F31 Ruth L. Kirschstein National Research Service Award for Individual Pre-doctoral Fellows [1F31AI080160-01A1]. The authors declare that they have no conflicts of interest related to this work.

$\mathrm{MCH}$, SLP, and DMH designed the study; $\mathrm{MCH}$ conducted field mosquito sampling; $\mathrm{MCH}$ and LTK completed mosquito identification; BLB, CAT, and $\mathrm{MCH}$ analysed data; and $\mathrm{MCH}$, SLP, BLB, CAT, and DMH wrote the paper.

\section{Supporting Information}

Additional supporting information may be found online in the Supporting Information section at the end of the article.

Table S1. Total number of female mosquitoes per species collected by gravid traps from 2008 to 2010 across four forest logging treatments in southwestern Virginia. SASAB, Southern Appalachian Silviculture and Biodiversity Project. Mosquitoes from the genus Psorophora were not identified to the species level.

Table S2. Parameter effect tests for the model of total mosquito abundance. All parameter estimates are in reference to CCON sites in Craig County in August (BB1, Blacksburg 1; BB2, Blacksburg 2; BB3, Blacksburg 3; NC, Newcastle). Global model results are presented in the main manuscript. Significant differences from the reference $(P<0.05)$ are bolded.

Table S3. Parameter effect tests for the model of Aedes japonicus abundance. All parameter estimates are in reference to CCON sites in Craig County in August (BB1, Blacksburg 1; BB2, Blacksburg 2; BB3, Blacksburg 3; NC, Newcastle). Global model results are presented in the main manuscript. Significant differences $(P<0.05)$ are in bold.

Table S4. Parameter effect tests for the model of Aedes triseriatus abundance. All parameter estimates are in reference to CCON sites in Craig County in August (BB1, Blacksburg 1; BB2, Blacksburg 2; BB3, Blacksburg 3; NC, Newcastle). Global model results are presented in the main manuscript. Significant differences $(P<0.05)$ are in bold.

Table S5. Parameter effect tests for the model of Culex pipiens/restuans abundance. All parameter estimates are in reference to CCON sites in Craig County in August (BB1, Blacksburg 1; BB2, Blacksburg 2; BB3, Blacksburg 3; NC, Newcastle). Global model results are presented in the main manuscript. Significant differences $(P<0.05)$ are in bold.

\section{References}

Allan, B.F., Langerhans, R.B., Ryberg, W.A., Landesman, W.J., Griffin, N.W., Katz, R.S. et al. (2009) Ecological correlates of risk and incidence of West Nile virus in the United States. Oecologia, 158, 699-708.

Anderson, M.J. (2001) A new method for non-parametric multivariate analysis of variance. Austral Ecology, 26, 32-46.

Antonovics, J., Iwasa, Y. \& Hassell, M.P. (1995) A generalized-model of parasitoid, venereal, and vector-based transmission processes. American Naturalist, 145, 661-675.

Atwood, C.J. (2008) Effects of Alternative Silvicultural Treatments on Regeneration in the Southern Appalachians. Virginia Tech, Blacksburg, Virginia.

Atwood, C.J., Fox, T.R. \& Loftis, D.L. (2009) Effects of alternative silviculture on stump sprouting in the southern Appalachians. Forest Ecology and Management, 257, 1305-1313.

Barros, F.S. \& Honório, N.A. (2015) Deforestation and malaria on the Amazon frontier: larval clustering of Anopheles (Diptera: Culicidae) determines focal distribution of malaria. American Journal of Tropical Medicine and Hygiene, 93, 939-953.

Batzer, D.P., George, B.M. \& Braccia, A. (2005) Aquatic invertebrate responses to timber harvest in a bottomland hardwood wetland of South Carolina. Forest Science, 51, 284-291.

Belote, R.T., Jones, R.H., Hood, S.M. \& Wender, B.W. (2008) Diversity-invasibility across an experimental disturbance gradient in Appalachian forests. Ecology, 89, 183-192.

Bova, J.E. (2014) Morphological differentiation of eggs and comparative efficacy of oviposition and gravid traps for Aedes vectors at different habitats. Doctoral dissertation, Virginia Tech, Blacksburg, Virginia.

Burivalova, Z., Şekerioğlu, Ç. \& Koh, L.P. (2014) Thresholds of logging intensity to maintain tropical forest biodiversity. Current Biology, 24, 1893-1898.

Chen, Y.-C., Wang, C.-Y., Teng, H.-J., Chen, C.-F., Chang, M.-C., Lu, L.C. et al. (2011) Comparison of the efficacy of $\mathrm{CO}_{2}$-baited and unbaited light traps, gravid traps, backpack aspirators, and sweep net collections for sampling mosquitoes infected with Japanese encephalitis virus. Journal of Vector Ecology, 36, 68-74.

Couret, J., Dotson, E. \& Benedict, M.Q. (2014) Temperature, larval diet, and density effects on development rate and survival of Aedes aegypti (Diptera: Culicidae). PLoS One, 9, e87468.

Darsie, R.F. Jr. (2002) Revision of Darsie and Ward (1981) to include Ochlerotatus japonicus Theobold and a checklist of species referred to the genus Ochlerotatus in the Nearctic Region. Journal of the American Mosquito Control Association, 18, 237-240.

Duraes, R., Carrasco, L., Smith, T.B. \& Karubian, J. (2013) Effects of forest disturbance and habitat loss on avian communities in a Neotropical biodiversity hotspot. Biological Conservation, 166, 203-211.

Ewers, R.M., Boyle, M.J.M., Gleave, R.A., Plowman, N.S., Benedick, S., Bernard, H. et al. (2015) Logging cuts the functional importance of invertebrates in tropical rainforest. Nature Communications, $6,6836$.

Farajollahi, A., Fonseca, D.M., Kramer, L.D. \& Kilpatrick, A.M. (2011) "Bird biting" mosquitoes and human disease: a review of the role of Culex pipiens complex mosquitoes in epidemiology. Infection Genetics and Evolution, 11, 1577-1585.

Ferraguti, M., Martínez-de La Puente, J., Roiz, D., Ruiz, S., Soriguer, R. \& Figuerola, J. (2016) Effects of landscape anthropization on mosquito community composition and abundance. Scientific Reports, 6, 29002 .

Gardner, A.M., Lampman, R.L. \& Muturi, E.J. (2014) Land use patterns and the risk of West Nile virus transmission in central Illinois. Vector-Borne and Zoonotic Diseases, 14, 338-345. 
Ghazoul, J. (2002) Impact of logging on the richness and diversity of forest butterflies in a tropical dry forest in Thailand. Biodiversity and Conservation, 11, 521-541.

Haddow, A.D., Bixler, D. \& Schuh, A.J. (2011) The demographic and socioeconomic factors predictive for populations at high-risk for La Crosse virus infection in West Virginia. PLoS One, 6, e25739.

Hansen, M.C., Potapov, P.V., Moore, R., Hancher, M., Turubanova, S.A., Tyukavina, A. et al. (2013) High-resolution global maps of $21^{\text {st }}$-century forest cover change. Science, $342,850-853$.

Harkness, L.M., Drohan, A.E., Dickson, C.M. \& Smith, T.G. (2010) Experimental transmission of Hepatozoon clamatae (Apicomplexa: Adeleida) to the Wood Frog, Rana sylvatica, and to the mosquito Culex pipiens. Journal of Parasitology, 96, 434-436.

Harrington, L.C. \& Poulson, R.L. (2008) Considerations for accurate identification of adult Culex restuans (Diptera : Culicidae) in field studies. Journal of Medical Entomology, 45, 1-8.

Harris, M.C., Dotseth, E.J., Jackson, B.T., Zink, S.D., Marek, P.E., Kramer, L.D. et al. (2015) La Crosse virus in Aedes japonicus japonicus mosquitoes in the Appalachian Region, USA. Emerging Infectious Diseases, 21, 646-649.

Homyack, J.A. \& Haas, C.A. (2013) Effects of repeated-stand entries on terrestrial salamanders and their habitat. Southeastern Naturalist, 12, 353-366.

Jackson, B.T. \& Paulson, S.L. (2006) Bionomics and seasonal abundance of Culex restuans and Culex pipiens in southwestern Virginia. Journal of the American Mosquito Control Association, 206, 206-212.

Jackson, B.T., Paulson, S.L., Youngman, R.R., Scheffel, S.L. \& Hawkins, B. (2005) Oviposition preferences of Culex restuans and Culex pipiens (Diptera: Culicidae) for selected infusions in oviposition traps and gravid traps. Journal of the American Mosquito Control Association, 21, 360-365.

Johnson, B.J., Robson, M.G. \& Fonseca, D.M. (2015) Unexpected spatiotemporal abundance of infected Culex restuans suggest a greater role as a West Nile virus vector for this native species. Infection, Genetics, and Evolution, 31, 40-47.

Johnson, M.F., Gomez, A. \& Pinedo-Vasquez, M. (2008) Land use and mosquito diversity in the Peruvian Amazon. Journal of Medical Entomology, 45, 1023-1030.

Jost, L. (2009) Partitioning diversity into independent alpha and beta components. Ecology, 90, 3593-3593.

Juliano, S.A. (2009) Species interactions among larval mosquitoes: context dependence across habitat gradients. Annual Review of Entomology, 54, 37-56.

Karki, S., Hamer, G.L., Anderson, T.K., Goldberg, T.L., Kitron, U.D., Krebs, B.L. et al. (2016) Effect of trapping methods, weather, and landscape on estimates of the Culex vector mosquito abundance. Environmental Health Insights, 10, 93-103.

Kaufman, M.G. \& Fonseca, D.M. (2014) Invasion biology of Aedes japonicus japonicus (Diptera: Culicidae). Annual Review of Entomology, 59, 31-49.

Keesing, F., Holt, R.D. \& Ostfeld, R.S. (2006) Effects of species diversity on disease risk. Ecology Letters, 9, 485-498.

Keesing, F., Belden, L.K., Daszak, P., Dobson, A., Harvell, C.D., Holt, R.D. et al. (2010) Impacts of biodiversity on the emergence and transmission of infectious diseases. Nature, 468, 647-652.

Keylock, C.J. (2005) Simpson diversity and the Shannon-Wiener index as special cases of a generalized entropy. Oikos, 109, 203-207.

Kilpatrick, A.M., Fonseca, D.M., Ebel, G.D., Reddy, M.R. \& Kramer, L.D. (2010) Spatial and temporal variation in vector competence of Culex pipiens and Cx. restuans mosquitoes for West Nile Virus. American Journal of Tropical Medicine and Hygiene, 83, 607-613.
Kimura, M., Darbro, J.M. \& Harrington, L.C. (2010) Avian malaria parasites share congeneric mosquito vectors. Journal of Parasitology, 96, 144-151.

Kitching, R.L. (1971) An ecological study of water-filled tree-holes and their position in the woodland ecosystem. The Journal of Animal Ecology, 40, 281-302.

Kruskal, J.B. (1964) Multidimensional scaling by optimizing goodness of fit to a nonmetric hypothesis. Psychometrika, 29, 1-27.

Ledesma, N. \& Harrington, L. (2011) Mosquito vectors of dog heartworm in the United States: vector status and factors influencing transmission efficiency. Topics in Companion Animal Medicine, 26, $178-185$.

Legendre, P. \& Legendre, L. (1998) Numerical Ecology. Elsevier, Amsterdam, The Netherlands.

Mather, T.N., Nicholson, M.C., Donnelly, E.F. \& Matyas, B.T. (1996) Entomologic index for human risk of Lyme disease. American Journal of Epidemiology, 144, 1066-1069.

McCune, B. \& Grace, J.B. (2002) Analysis of Ecological Communities. MjM Software Design, Gleneden Beach, Oregon.

McJunkin, J.E., Khan, R.R. \& Tsai, T.F. (1998) California La Crosse encephalitis. Infectious Disease Clinics of North America, 12, 83-93.

Mehus, J.O. \& Vaughan, J.A. (2013) Molecular identification of vertebrate and hemoparasite DNA within mosquito blood meals from eastern North Dakota. Vector-Borne and Zoonotic Diseases, 13, 818-824.

Meyer Steiger, D.B., Ritchie, S.A. \& Laurance, S.G. (2016) Mosquito communities and disease risk influenced by land use change and seasonality in the Australian tropics. Parasites \& Vectors, 9, 387.

Nupp, T.E. \& Swihart, R.K. (1998) Effects of forest fragmentation on population attributes of whitefooted mice and eastern chipmunks. Journal of Mammology, 79, 1234-1243.

O'Brien, V.A. \& Reiskind, M.H. (2013) Host-seeking mosquito distribution in habitat mosaics of southern Great Plains cross-timbers. Journal of Medical Entomology, 50, 1231-1239.

Pongsiri, M.J., Roman, J., Ezenwa, V.O., Goldberg, T.L., Koren, H.S., Newbold, S.C. et al. (2009) Biodiversity loss affects global disease ecology. Bioscience, 59, 945-954.

R Core Team (2016) R: A Language and Environment for Statistical Computing. R Foundation for Statistical Computing, Vienna, Austria.

Reiter, P. (1986) A standardized procedure for the quantitative surveillance of certain Culex mosquitoes by egg raft collection. Journal of the American Mosquito Control Association, 2, 219-221.

Reiter, P., Jakob, W., Francy, D. \& Mullenix, J. (1986) Evaluation of the CDC gravid trap for the surveillance of St. Louis encephalitis vectors in Memphis, Tennessee. Journal of the American Mosquito Control Association, 2, 209-211.

Sardelis, M.R. \& Turell, M.J. (2001) Ochlerotatus j. japonicus in Frederick County, Maryland: discovery, distribution, and vector competence for West Nile virus. Journal of the American Mosquito Control Association, 17, 137-141.

Sardelis, M.R., Turell, M.J. \& Andre, R.G. (2002) Laboratory transmission of La Crosse virus by Ochlerotatus j. japonicus (Diptera: Culicidae). Journal of Medical Entomology, 39, 635-639.

Saul, S.H., Grimstad, P.R. \& Craig, G.B. (1977) Identification of Culex species by electrophoresis. American Journal of Tropical Medicine and Hygiene, 26, 1009-1012.

Savilaakso, S., Koivisto, J., Veteli, T.O., Pusenius, J. \& Roininen, H. (2009) Long lasting impact of forest harvesting on the diversity of herbivorous insects. Biodiversity and Conservation, 18, 3931-3948.

Scott, J.J., Crans, S.C. \& Crans, W.J. (2001) Use of an infusion-baited gravid trap to collect adult Ochlerotatus japonicus. Journal of the American Mosquito Control Association, 17, 142-143.

Slaff, M. \& Apperson, C.S. (1989) A key to the mosquitoes of North Carolina and the Mid-Atlantic states. Agricultural Extension Service, North Carolina State University, Raleigh, North Carolina. 
Smith, T.G., Kopko, S.H. \& Desser, S.S. (1996) Life cycles, morphological characteristics, and host specificity of Hepatozoon species infecting eastern garter snakes from Ontario. Canadian Journal of Zoology, 74, 1850-1856.

Strehlow, K., Bradley, J.S., Davis, J. \& Friend, G.R. (2002) Short term impacts of logging on invertebrate communities in jarrah forests in south-west Western Australia. Forest Ecology and Management, 162, $165-184$.

Szumlas, D.E., Apperson, C.S. \& Powell, E.E. (1996) Seasonal occurrence and abundance of Aedes triseriatus and other mosquitoes in a La Crosse virus-endemic area in western North Carolina. Journal of the American Mosquito Control Association, 12, 184-193.

Thongsripong, P., Green, A., Kittayapong, P., Kapan, D., Wilcox, B. \& Bennett, S. (2013) Mosquito vector diversity across habitats in central Thailand endemic for dengue and other arthropod-borne diseases. PLoS Neglected Tropical Diseases, 7, e2507.

Tilman, D., Balzer, C., Hill, J. \& Befort, B.L. (2011) Global food demand and the sustainable intensification of agriculture. Proceedings of the National Academy of Sciences of the United States of America, 108, 20260-20264.

Turell, M.J., O’Guinn, M.L., Dohm, D.J. \& Jones, J.W. (2001) Vector competence of North American mosquitoes (Diptera: Culicidae) for West Nile virus. Journal of Medical Entomology, 38, $130-134$

Turell, M.J., Dohm, D.J., Sardelis, M.R., Oguinn, M.L., Andreadis, T.G. \& Blow, J.A. (2005) An update on the potential of North American mosquitoes (Diptera: Culicidae) to transmit West Nile virus. Journal of Medical Entomology, 42, 57-62.

Venables, W.N. \& Ripley, B.D. (2002) Modern Applied Statistics with $S$, 4th edn. Springer, New York, New York.

Walsh, J.F., Molyneux, D.H. \& Birley, M.H. (1993) Deforestation: effects on vector-borne disease. Parasitology, 106, S55-S75.
Watts, D.M., Morris, C.D., Wright, R.E., DeFoliart, G.R. \& Hanson, R.P. (1972) Transmission of LaCrosse virus (California encephalitis group) by the mosquito Aedes triseriatus. Journal of Medical Entomology, 9, 125-127.

Williams, G.M. \& Gingrich, J.B. (2007) Comparison of light traps, gravid traps, and resting boxes for West Nile virus surveillance. Journal of Vector Ecology, 32, 285-291.

Yang, F., Chan, K., Marek, P.E., Armstrong, P.M., Liu, P., Bova, J.E. et al. (2018) Cache Valley virus in Aedes japonicus japonicus mosquitoes, Appalachian Region, United States. Emerging Infectious Diseases, 24, 553-557. https://doi.org/10.3201/eid2403.161275.

Yasuoka, J. \& Levins, R. (2007) Impact of deforestation and agricultural development on Anopheline ecology and malaria epidemiology. American Journal of Tropical Medicine and Hygiene, 76, 450-460.

Yee, D.A., Allgood, D., JKneitel, J.M. \& Kuehn, K.A. (2012) Constitutive differences between natural and artificial container mosquito habitats: vector communities, resources, microorganisms, and habitat parameters. Journal of Medical Entomology, 49, 482-491.

Zhody, S., Derfus, K., Headrick, E.G., Tovo Andrianjafy, M., Wright, P.C. \& Gillespie, T.R. (2016) Small-scale land-use variability affects Anopheles spp. distribution and concomitant Plasmodium infection in humans and mosquito vectors in southeastern Madagascar. Malaria Journal, 15, 114.

Zhong, D., Wang, X., Xu, T., Zhou, G., Wang, Y., Lee, M.-C. et al. (2016) Effects of microclimate condition changes due to land use and land cover changes on the survivorship of malaria vectors in China-Myanmar border region. PLoS One, 11, e0155301.

Accepted 7 February 2018

First published online 13 March 2018

Associate Editor: Simon Leather 